\title{
Rate coefficients and product branching ratios for the oxidation of phenyl and naphthyl radicals: A theoretical RRKM-ME study
}

\author{
V. V. Kislov ${ }^{\mathrm{a}}$, R. I. Singh ${ }^{\mathrm{b}}$, D. E. Edwards ${ }^{\mathrm{b}, \mathrm{c}}$, A. M. Mebel ${ }^{\mathrm{a},{ }^{,}}$, M. Frenklach $^{\mathrm{b}, \mathrm{c}}$ \\ ${ }^{\mathrm{a}}$ Department of Chemistry and Biochemistry, Florida International University, Miami, FL 33199, USA \\ ${ }^{\mathrm{b}}$ Department of Mechanical Engineering, University of California at Berkeley, Berkeley, CA 94720, USA \\ ${ }^{\mathrm{c}}$ Environmental Energy Technologies Division, Lawrence Berkeley National Laboratory, Berkeley, CA, 94720, USA
}

Corresponding Author: $\quad$ Name: Alexander M. Mebel

Street address: CP 332

Department: Department of Chemistry and Biochemisttry

University: Florida International University

University Address: $11200 \mathrm{SW} 8^{\text {th }}$ Street, Miami, FL 33199, USA

Phone: +1-305-348-1945

E-mail: mebela@fiu.edu

Colloquium Topic Area: $\quad$ Soot, PAH \& Other Large Molecules

Total length: $\quad 6199$ Words (Limit: 6200 words)

Main Text: 4270 words (MSWord word count)

Equations: 0

References: $\quad(33$ references +2$) \times(2.3$ lines $/$ reference $) \times(7.6$ words $/$ line $)=612$ words

Table 1: $\quad(4$ text lines +2 lines $) \times 7.6$ words $/$ line $\times 1$ column $=46$ words

Figure 1: $\quad[48 \mathrm{~mm}+10 \mathrm{~mm}] \times 2.2$ words $/ \mathrm{mm} \times 1$ column +22 words in caption $=150$ words

Figure 2: $\quad[185 \mathrm{~mm}+10 \mathrm{~mm}] \times 2.2$ words $/ \mathrm{mm} \times 1$ columns +28 words in caption $=457$ words

Figure 3: $\quad[132 \mathrm{~mm}+10 \mathrm{~mm}] \times 2.2$ words $/ \mathrm{mm} \times 2$ column +39 words in caption $=664$ words

Supplemental Material has been included in the submission of this paper.

Submitted to the $35^{\text {th }}$ International Symposium on Combustion, San Francisco, CA, August 3-8, 2014. 
Abstract. Theoretical VRC-TST/RRKM-ME calculations were performed to evaluate total rate coefficients and product branching ratios for the oxidation of phenyl and 1- and 2-naphthyl radicals with $\mathrm{O}_{2}$ at temperatures relevant to combustion $(1500,2000$, and $2500 \mathrm{~K})$ and pressures of $0.01,0.1,1.0$, and $10 \mathrm{~atm}$. The results give the rate coefficients in the range of $3.0-5.5 \times 10^{-11} \mathrm{~cm}^{3}$ molecule $\mathrm{s}^{-1}$ with slightly positive temperature dependence, activation energies varying within $2.3-3.3 \mathrm{kcal} / \mathrm{mol}$, and preexponential factors of $7-10 \times 10^{-11} \mathrm{~cm}^{3}$ molecule $\mathrm{s}^{-1}$. The dominant reaction channel in all three cases is elimination of the oxygen atom from peroxy complexes formed at the initial $\mathrm{O}_{2}$ addition step and leading to the phenoxy and naphthoxy radical products. The contribution of this channel increases with temperature. Chemically-activated phenoxy and naphthoxy radicals either decompose to the cyclopentadienyl+CO and indenyl+CO products, respectively, or undergo thermal equilibration. The relative yields of the decomposition/equilibration products strongly depend on temperature and pressure in the way that a temperature growth favors decomposition, whereas an increase in pressure favors equilibration. At the lowest temperature considered, $1500 \mathrm{~K}$, the reactions also yield significant amounts of pyranyl $+\mathrm{CO}\left(\right.$ phenyl $\left.+\mathrm{O}_{2}\right)$ or 1-benzopyranyl+CO (1-naphthyl $\left.+\mathrm{O}_{2}\right)$. A comparison of the phenyl+O $\mathrm{O}_{2}$ and naphthyl $+\mathrm{O}_{2}$ reactions reveals that although the general trends in the oxidation kinetics of phenyl and naphthyl radicals are similar, the size and especially the position of the radical site in the aromatic moiety may affect the details of the mechanism and relative product yields.

Keywords: Oxidation, Reaction mechanisms, PAH, Soot 


\section{Introduction}

The reactions of aromatic radicals with molecular oxygen play an import role in combustion of hydrocarbon fuels. The oxidation reactions on one hand compete with the formation of polycyclic aromatic hydrocarbons $(\mathrm{PAH})$ in combustion flames but on the other hand, produce smaller species. Some of them contain five-member rings, such as cyclopentadienyl and indenyl, which in turn, propagate further PAH synthesis and thus contribute to the formation of a large variety of cyclopentafused PAH. In addition, oxidation generates energy for further growth processes [1].

Phenyl and naphthyl are prototypes of single and multi-ring aromatic radicals. A detailed theoretical analysis of the mechanism and kinetics of their reactions with $\mathrm{O}_{2}$ is sought to better understand how larger PAH radicals are oxidized in flames. The mechanism and kinetics of the $\mathrm{C}_{6} \mathrm{H}_{5}+\mathrm{O}_{2}$ reaction has received considerable attention by the combustion community in the last two decades [2-17].

Previously, Mebel and co-workers reported an extensive ab initio G2M study of the $\mathrm{C}_{6} \mathrm{H}_{5} \mathrm{O}_{2}$ potential energy surface (PES) to map out the detailed mechanism of the phenyl radical oxidation [12]. According to their study, the most energetically favorable reaction channels are those leading to the formation of cyclopentadienyl radicals $\mathrm{c}-\mathrm{C}_{5} \mathrm{H}_{5}$ together with $\mathrm{CO}+\mathrm{O}$ or $\mathrm{CO}_{2}$, followed by the channels producing pyranyl $+\mathrm{CO}$ and o-benzoquinone $+\mathrm{H}$. Noteworthy, the calculations showed that cyclic peroxides with five- or six-membered rings do not exist as stable local minima on the PES $[7,12]$. However, the PES by itself is not sufficient to predict reaction rate coefficients and product branching ratios at temperatures and pressures relevant to combustion.

Experimentally, rate coefficients for the $\mathrm{C}_{6} \mathrm{H}_{5}+\mathrm{O}_{2}$ reaction have been measured in two overlapping temperature ranges, 297-473 K ( $p=20-80$ Torr) [5] and 418-815 K ( $p=0.7$ mbar) [14], which are considerably lower than typical combustion temperatures. The canonical variational transition state theory (CVTST) calculations based on a density functional O3LYP/6-31G(d) potential reported by Silva and Bozzelli [13] reproduced the experimental rate coefficients for the $\mathrm{C}_{6} \mathrm{H}_{5}+\mathrm{O}_{2}$ association channel at temperatures close to $400 \mathrm{~K}$, but failed to describe the observed temperature dependence. A question of 
which reaction products can be formed under combustion conditions also remains open. Whereas at low temperatures the $\mathrm{C}_{6} \mathrm{H}_{5}+\mathrm{O}_{2}$ reaction has been shown to proceed via the addition-stabilization mechanism leading to the phenyl peroxy radical $\mathrm{C}_{6} \mathrm{H}_{5} \mathrm{OO}$ [5], at $T \geq 1000 \mathrm{~K}$ the reaction is believed to produce $\mathrm{C}_{6} \mathrm{H}_{5} \mathrm{O}+\mathrm{O}$ with further fragmentation of phenoxy radical yielding the $\mathrm{C}_{5} \mathrm{H}_{5}+\mathrm{CO}$ products $[5,6]$. Additionally, the minor reaction channels producing $o$ - and $p$-benzoquinone, $o / p-\mathrm{C}_{6} \mathrm{H}_{4} \mathrm{O}_{2}$, plus $\mathrm{H}$ atoms were also suggested [7]. However, the only products observed in the recent crossed molecular beam experiments at collision energies of 5-26 kcal mol ${ }^{-1}$ [15-17], which correspond to high combustion temperatures and beyond, were $\mathrm{C}_{6} \mathrm{H}_{5} \mathrm{O}+\mathrm{O}$.

The oxidation of the smallest all-six-member-ring PAH radical, naphthyl, is less studied. Marinov et al. [18] estimated the rate coefficient of the $1-\mathrm{C}_{10} \mathrm{H}_{7}+\mathrm{O}_{2}$ reaction producing $\mathrm{C}_{10} \mathrm{H}_{7} \mathrm{O}+\mathrm{O}$ in their kinetic modeling of a laminar premixed $n$-butane flame. Lin and co-workers have measured thermal rate coefficients for the 2-naphthyl $+\mathrm{O}_{2}$ system at temperatures of 299-444 K using cavity ring-down spectroscopy [19]. They also used G2MS//B3LYP/6-31+G(d,p) and CVTST calculations to compute the rate coefficients and reported a good agreement of their theoretical results with the experimental values. In terms of the reaction products, Lin and co-workers [19] proposed that at low temperatures the reaction proceeds via the association-stabilization mechanism forming the naphthyl peroxy radical $\mathrm{C}_{10} \mathrm{H}_{7} \mathrm{OO}$ which then may lose the terminal oxygen atom yielding the naphthoxy radical, $\mathrm{C}_{10} \mathrm{H}_{7} \mathrm{O}$. Mebel and co-workers [20] recently reported a detailed ab initio study for the reaction of 1- and 2naphthyl radicals with $\mathrm{O}_{2}$ augmented with a qualitative kinetic analysis. They computed rate coefficients for individual reaction steps at the high-pressure limit and product branching ratios in a steady-state regime. The simplified kinetic analysis revealed that some other products, such as indenyl+CO $2,1,2-$ naphthoquinone+H, and 1- and 2-benzopyranyls+CO may appear under combustion conditions. However, neither experimental nor theoretical data are available on pressure and temperature dependent product branching ratios. 
The goal of the present study is to theoretically predict thermal rate coefficients and product branching ratios for the phenyl $+\mathrm{O}_{2}$ and naphthyl $+\mathrm{O}_{2}$ reaction systems at the conditions relevant to combustion, which can be integrated into kinetic simulations of hydrocarbon flames. Our approach in achieving this goal is to apply current theoretical models for kinetic calculations, such as the variable reaction coordinate-transition state theory (VRC-TST) to treat the barrierless entrance channels and RRKM-Master Equation (RRKM-ME) simulations to compute product branching ratios in the overall reaction mechanism.

\section{Calculation Methods}

\subsection{Entrance channel reaction rate coefficients}

The VRC-TST calculations of thermal rate coefficients for barrierless phenyl $+\mathrm{O}_{2}$ and naphthyl $+\mathrm{O}_{2}$ association channels were carried out using the VARIFLEX code developed by Klippenstein and coworkers $[21,22]$. Briefly, the VRC-TST approach separates the transition state's degrees of freedom into "conserved" and "transitional" modes. The conserved modes marginally change over the reaction process and are treated as rigid rotors or harmonic oscillators by directly computing the corresponding sums of states. The transitional modes are treated classically through a phase-space integral. Then, the partition function of a transition state is calculated through a convolution of these two types of modes, by varying the distance along the reaction coordinate and recalculating the contribution of the transitional modes to the partition function until a minimum reaction rate is found [21].

To compute the potential along the minimal energy reaction path (MEP), i.e., the stretching potential, for the addition of $\mathrm{O}_{2}$ to $\mathrm{C}_{6} \mathrm{H}_{5}$, we scanned the PES by fixing the reaction coordinate, i.e., the $\mathrm{C}_{6} \mathrm{H}_{5}-\mathrm{O}_{2}$ bond distance $r\left(\mathrm{C}_{6} \mathrm{H}_{5}-\mathrm{O}_{2}\right)$, while fully optimizing all other geometric parameters. $r\left(\mathrm{C}_{6} \mathrm{H}_{5}-\mathrm{O}_{2}\right)$ was varied within the 1.4-4.0 $\AA$ range with a step size of $0.05 \AA$ and $\mathrm{C}_{\mathrm{s}}$ symmetry constraints were imposed with the $\mathrm{O}_{2}$ and $\mathrm{C}_{6} \mathrm{H}_{5}$ fragments lying in the same plane. The MEP potential was computed at two levels of theory, single-reference B3LYP/6-311++G** and multi-reference complete-active-space self- 
consistent-field CASSCF(9,9)/aug-cc-pVDZ. The potential obtained by the PES scan at the CASSCF $(9,9) /$ aug-cc-pVDZ level was further refined by single point energy calculations at the higher multi-reference second-order perturbation-theory CASPT2(19,14)/aug-cc-pVDZ level (further details of MEP calculations can be found in the Supplemental Material).

For the larger naphthyl+O $\mathrm{O}_{2}$ system, we used the CASPT2 $(19,14)$ stretching potential computed for the phenyl $+\mathrm{O}_{2}$ system scaled to reproduce the accurate $\mathrm{C}_{10} \mathrm{H}_{7}-\mathrm{O}_{2}$ bond dissociation energies in the 1and 2-naphthyl peroxy radicals computed at the G3(MP2,CC) level [20]. All density functional and ab initio calculations were carried out using the GAUSSIAN 98 [23], MOLPRO 2002 [24], and DALTON $2.0[25]$ program packages.

The computed stretching potentials for VARIFLEX calculations were provided in a tabulated form and then interpolated by the VARIFLEX built-in procedure. The anisotropy of the potential was taken into account by specifying the OOC and OCC angles corresponding to the equilibrium structures of phenylperoxy and naphthylperoxy radicals. The geometries, frequencies, and moments of inertia required for VRC-TST calculations were taken from the previous quantum mechanical studies [12,20]. The energy grain size and maximum energy value utilized in VARIFLEX calculations were identical to those values used in RRKM-ME simulations described in the following section.

The $\mathrm{O}$ atom loss from the $\mathrm{C}_{6} \mathrm{H}_{5} \mathrm{OO}$ intermediate $\mathbf{1}$ (Figure $\mathrm{S} 1$ ) and $\mathrm{C}_{10} \mathrm{H}_{7} \mathrm{OO}$ intermediates a1 (Figure S2) and b1 (Figure S6) occurs via distinct transition states followed by weakly bound van der Waals complexes 2, a2, and b2, respectively. However, at high temperatures considered in the present study, the tight transition states, such as that between $\mathbf{1}$ and the $\mathrm{C}_{6} \mathrm{H}_{5} \mathrm{O} \ldots \mathrm{O}$ complex $\mathbf{2}$ and its analogs in the naphthyl+O $\mathrm{O}_{2}$ system, represent kinetic bottlenecks for the dissociation (O loss) processes and the complexes do not play any kinetic role. Therefore, the rate coefficients for the oxygen atom loss from $\mathbf{1}$, a1, and b1 were computed using the distinct transition states leading to the van der Waals complexes.

\subsection{RRKM-ME calculations of product branching ratios}


The rate coefficients of the chemically-activated reaction systems were computed using the MultiWell 2012.2 code [26-28] for the phenyl $+\mathrm{O}_{2}$ and naphthyl $+\mathrm{O}_{2}$ reaction mechanisms from the PESs published earlier and shown in the Supplemental Material (see Figures S1-S9). MultiWell solves the onedimensional time-dependent energy-transfer master equations for a multi-well and multi-channel unimolecular reaction system using the Monte Carlo stochastic method. Microcanonical rate coefficients for all elementary reactions involved were computed with MultiWell at the RRKM level.

Key parameters required for MultiWell simulations, such as reaction barriers, frequencies, and moments of inertia, were taken from the previous calculations [12,20]. Following Gilbert and Smith [29], vibrational frequencies were examined by graphically visualizing the associated normal mode vibrations to identify internal rotational modes and, accordingly, all internal rotors were treated as 1-D hindered rotors. The microcanonical rate constants for the barrierless entrance reactions (computed by VARIFLEX as described in the previous section) were read into MultiWell and directly incorporated into the ME simulation.

Reaction rates were computed at three different temperatures of 1500,2000 , and $2500 \mathrm{~K}$ and pressures of $0.01,0.1,1.0$, and $10 \mathrm{~atm}$. In the future, we plan to continue our study to give comprehensive rate coefficients (including lower temperatures and higher pressures) to all channels. Argon was chosen as the bath gas collider. The exponential-down model with $\langle\Delta E\rangle_{\mathrm{down}}=260 \mathrm{~cm}^{-1}$ was used to describe the collisional energy transfer [30]. Lennard-Jones parameters were estimated from an empirical correlation [31]. The exact count, with an energy grain size of $10 \mathrm{~cm}^{-1}$ for the first segment of the double array and a maximum energy of $500,000 \mathrm{~cm}^{-1}$, was employed to determine the density of states. For each set of initial conditions, the number of trials was varied to keep statistical error below $5 \%$.

The chemical-activated rate coefficients were derived from the accumulated species fractions of the products, as we have done previously [32]. The accumulated species fractions were found by running a MultiWell simulation started with a chemical-activated initial energy distribution. The species fractions were found after the average energy of the initial adduct converges, indicating the end of the chemically- 
activated simulation. Simulation times ranged from $10^{-8} \mathrm{~s}(T=2500 \mathrm{~K}, p=10 \mathrm{~atm})$ to $8 \times 10^{-5} \mathrm{~s}$ for $(T=1500$ $\mathrm{K}, p=0.01 \mathrm{~atm})$. Product formation rates were obtained by multiplying the species fractions of the products by the high-pressure reaction rate coefficient of the adduct formation reaction. Our solution is independent of time. The evolving populations as a sum of the direct and indirect routes is also a description of a real kinetic system, and similar tools, as described here and in [32], are used to extract phenomenological rate constants.

\section{Results and Discussion}

\subsection{Overall thermal rate coefficients}

It is imperative to compare the computed overall phenyl $+\mathrm{O}_{2} \rightarrow$ products rate coefficients with the available experimental data. Since our goal is to generate reliable rate coefficients for combustion temperatures, we focus our comparison on the higher-temperature data set reported by Schaugg and coworkers for the $418-815 \mathrm{~K}$ temperature range and $p=0.7$ mbar measured using a fast flow reactor technique [14]. As seen in Figure 1, the VRC-TST/RRKM-ME calculations closely reproduce Schaugg's experiment. The difference between the calculated and measured rate coefficients is within a factor of $1.4-2.0$ at higher temperatures $(656-815 \mathrm{~K})$ and slightly increases to a factor of 3.0 at $418 \mathrm{~K}$. The calculated rate coefficients show positive temperature dependence, which is consistent with the experiment; the fitted Arrhenius expression gives the activation energy of $1.9 \mathrm{kcal} / \mathrm{mol}$, only slightly higher than the apparent activation energy of $0.6 \mathrm{kcal} / \mathrm{mol}$ observed in experiment. The agreement between the theoretical and experimental activation energies is even better within the higher temperature 724-815 K range, where the measured rate coefficients exhibit strong Arrhenius-like behavior with $E_{\mathrm{a}}=$

\section{$2.2 \mathrm{kcal} / \mathrm{mol}$.}

One can expect that our theoretical rate coefficients calculated at temperatures relevant to combustion should be accurate within $40 \%$ or better as the agreement between experiment and theoretical predictions improves with temperature. Meanwhile, the larger deviation observed at low temperatures ( $T$ 
$=418 \mathrm{~K})$ may be attributed to the fact that computed rate coefficients are much more sensitive to inaccuracies in the stretching potential and in the theoretical approach in general, the factors which affect theoretical rate coefficients more significantly at lower temperatures than at high temperatures. Interestingly, the low-temperature kinetic measurements reported by Yu and Lin [5] for the 297-473 K temperature range and pressures of $20-80$ Torr show a negative activation energy of $-0.32 \mathrm{kcal} / \mathrm{mol}$, although in the temperature range where the two experimental data sets overlap, $418-473 \mathrm{~K}$, the rate coefficients obtained by $\mathrm{Yu}$ and Lin are in close agreement with those measured by Schaugg et al.

The available experimental data suggest that the rate coefficient has a minimum at around $400 \mathrm{~K}$. Such a behavior can be explained by the fact that the bimolecular rate coefficient is proportional to $\exp \left(\Delta S^{\#} / R\right) \times T^{2} \times \exp \left(-\Delta H^{\#} / R T\right)$ and even though the reaction is barrierless and thus has a negative $\Delta H^{\#}$, as the temperature rises, the decrease of $\exp \left(-\Delta H^{\#} / R T\right)$ appears to be slower than the increase of $T^{2}$ in the pre-exponential factor. A physical reason for the rate coefficient to pass through the minimum could be the role played by two (entrance and exit) transition states. At low temperatures the loose, barrierless association TS is dominant and the rate constant decreases with increasing temperature. At high temperatures the tight TS separating intermediate $\mathbf{1}$ from van der Waals complex $\mathbf{2}$ dominates and the reaction behaves qualitatively like it has a single TS with essentially no barrier - the rate coefficient increases with increasing temperature. Noteworthy is that our calculations correctly reproduced the positive temperature dependence of the rate coefficient at higher temperatures, whereas the earlier calculations by Silva and Bozzelli [13] did not.

Rate coefficients for the phenyl $+\mathrm{O}_{2}$ and 1- and 2-naphthyl $+\mathrm{O}_{2}$ reactions computed at combustionrelevant temperatures of $1500-2500 \mathrm{~K}$ are collected in Table 1 . Since the total rate coefficients are practically pressure-independent, only the values computed at 1 atm are presented in Table 1, whereas the data for the other pressures $(0.01,0.1$, and $10 \mathrm{~atm})$ are given in the Supplemental Material (Tables S1-S15). The results demonstrate that $k_{\text {total }}\left(\right.$ phenyl $\left.+\mathrm{O}_{2}\right)$ and $k_{\text {total }}\left(1-\right.$ naphthyl $\left.+\mathrm{O}_{2}\right)$ are in the range of 3.0$4.2 \times 10^{-11} \mathrm{~cm}^{3}$ molecule $\mathrm{e}^{-1} \mathrm{~s}^{-1}$ and are close to each other at the same temperatures, with differences not 
exceeding $10 \%$. In contrast, $k_{\text {total }}\left(2\right.$-naphthyl $\left.+\mathrm{O}_{2}\right)$ is computed to be $15-32 \%$ higher, in the range of 3.5-5.5 $\times 10^{-11} \mathrm{~cm}^{3}$ molecule $\mathrm{s}^{-1}$. A simple Arrhenius fit of the computed rate coefficients gives the $A$ factors of $6.68 \times 10^{-11}, 6.77 \times 10^{-11}$, and $1.05 \times 10^{-10} \mathrm{~cm}^{3}$ molecule $\mathrm{s}^{-1} \mathrm{~s}^{-1}$ for the phenyl+O $\mathrm{O}_{2}, 1-$ naphthyl+O $\mathrm{O}_{2}$, and 2-naphthyl $+\mathrm{O}_{2}$ reactions, respectively, with the corresponding activation energies being 2.47, 2.33, and $3.27 \mathrm{kcal} / \mathrm{mol}$, respectively.

\subsection{Product branching ratios and individual rate coefficients for product formation}

Considering the phenyl $+\mathrm{O}_{2}$ system, the reaction products include phenoxy radical $\mathrm{C}_{6} \mathrm{H}_{5} \mathrm{O}+\mathrm{O}$, pyranyl $\mathrm{C}_{5} \mathrm{OH}_{5}+\mathrm{CO}, \mathrm{C}_{5} \mathrm{H}_{5}+\mathrm{CO}_{2}$, and 1,2-benzoquinone $\mathrm{C}_{6} \mathrm{H}_{4} \mathrm{O}_{2}+\mathrm{H}$ [12]. Phenoxy radical, due to its chemical activation, can further dissociate to cyclopentadienyl $\mathrm{C}_{5} \mathrm{H}_{5}+\mathrm{CO}$. For the 1-(2-)naphthyl $+\mathrm{O}_{2}$ systems, the predicted reaction products include 1-(2-)naphthoxy 1-(2-) $\mathrm{C}_{10} \mathrm{H}_{7} \mathrm{O}+\mathrm{O}, 1-(2-)$ benzopyranyl 1-(2-) $\mathrm{C}_{9} \mathrm{OH}_{7}+\mathrm{CO}$, and 1,2-naphthoquinone 1,2- $\mathrm{C}_{10} \mathrm{H}_{6} \mathrm{O}_{2}+\mathrm{H}$ [20]. Chemically-activated naphthoxy radicals can further decompose to indenyl $\mathrm{C}_{9} \mathrm{H}_{7}+\mathrm{CO}$.

An important finding of our RRKM-ME simulation is the fact that collisionally stabilized intermediates were practically not detected as products in the temperature range of $1500-2500 \mathrm{~K}$ and at all studied pressures. The fact that there is no stabilization of the initial adduct was verified based on the output of MultiWell calculations, which provides an average energy of each potential well at each time. Using this, we tracked the energy of the initial adduct and confirmed that it is in an excited state even after the species fractions has dropped to insignificant levels (less than $10^{-4}$ ). This allowed us to conclude that no stabilization followed by thermal decomposition has occurred. The MultiWell calculations performed at four different pressures revealed that the combined yield of phenoxy radical and its decomposition product $\mathrm{C}_{5} \mathrm{H}_{5}+\mathrm{CO}$ as well as the combined yields of 1- or 2-naphthoxy radicals and their decomposition product indenyl $+\mathrm{CO}$, are pressure-independent. The same is true for the branching ratios of all other reaction products. Hence, Figure 2 shows plots of the branching ratios only as functions of temperature. 
The oxygen atom elimination, leading to phenoxy+O and eventually to $\mathrm{C}_{5} \mathrm{H}_{5}+\mathrm{CO}+\mathrm{O}$, is the dominant reaction channel for the phenyl+O $\mathrm{O}_{2}$ system, with its branching ratio increasing from 0.83 at $1500 \mathrm{~K}$ to 0.97 at $2500 \mathrm{~K}$. The second significant channel is pyranyl+CO with the highest yield of 0.10 observed at the lowest temperature of $1500 \mathrm{~K}$. For all other products, including $\mathrm{C}_{5} \mathrm{H}_{5}+\mathrm{CO}_{2}$ and $1,2-\mathrm{C}_{6} \mathrm{H}_{4} \mathrm{O}_{2}+\mathrm{H}$, the branching ratios do not exceed 0.05 . The product yields are similar for the 2-naphthyl+O $\mathrm{O}_{2}$ reaction, where the combined branching ratio of the 2-naphthoxy+O/indenyl+CO products increases from 0.81 at $1500 \mathrm{~K}$ to 0.95 at $2500 \mathrm{~K}$. The only slight difference from the phenyl+O $\mathrm{O}_{2}$ system is that the relative yields of the other products are nearly equally distributed at 0.06-0.07 (1500 K), 0.03-0.04 (2000 K), and 0.01-0.02 (2500 K).

The 1-naphthyl $+\mathrm{O}_{2}$ reaction displays a somewhat distinct behavior. The $\mathrm{O}$ atom elimination channel leading to 1-naphthoxy and then to indenyl+CO is still the major channel, with its branching ratio increasing from 0.51 to 0.77 with temperature. However, the contributions of the other channels are more significant than those for the phenyl $+\mathrm{O}_{2}$ and 2-naphthyl $+\mathrm{O}_{2}$ reactions; for instance, the branching ratios of 1-benzopyranyl+CO, $1,2-\mathrm{C}_{10} \mathrm{H}_{6} \mathrm{O}_{2}+\mathrm{H}$, and indenyl $+\mathrm{CO}_{2}$ range from $0.24,0.14$, and 0.11 at $1500 \mathrm{~K}$ to $0.13,0.07$, and 0.03 at $2500 \mathrm{~K}$, respectively. The higher yields of these other products formed after an $\mathrm{O}$ atom insertion into the aromatic ring in the 1-naphthyl+O $\mathrm{O}_{2}$ reaction correlates well with the relative energy of the transition state for this insertion, $-25.5 \mathrm{kcal} / \mathrm{mol}$ with respect to the initial reactants, that is substantially lower than the corresponding values for the phenyl+O $\mathrm{O}_{2}$ and 2-naphthyl+O $\mathrm{O}_{2}$ reactions, -18.9 and $-20.0 \mathrm{kcal} / \mathrm{mol}$, respectively $[12,20]$.

The phenoxy and naphthoxy radicals formed after elimination of an $\mathrm{O}$ atom from the initial phenyl peroxy and naphthyl peroxy radical complexes can further dissociate to $\mathrm{C}_{5} \mathrm{H}_{5}+\mathrm{CO}$ or indenyl+CO due to their chemical activation or, alternatively, can be thermally equilibrated by collisions. The equilibrated species may then undergo thermal decomposition but we do not consider this secondary reaction mechanism in the present study and count the equilibrated $\mathrm{C}_{6} \mathrm{H}_{5} \mathrm{O}$ and $1-/ 2-\mathrm{C}_{10} \mathrm{H}_{7} \mathrm{O}$ radicals as final products of the primary reactions. 
The MultiWell calculations reveal that the branching ratios of $\mathrm{C}_{6} \mathrm{H}_{5} \mathrm{O}+\mathrm{O}$ vs. $\mathrm{C}_{5} \mathrm{H}_{5}+\mathrm{CO}+\mathrm{O}$ and of 1/2- $\mathrm{C}_{10} \mathrm{H}_{7} \mathrm{O}+\mathrm{O}$ vs. indenyl $+\mathrm{CO}+\mathrm{O}$ strongly depend both on temperature and pressure. Figure 3 shows rate coefficients for the formation of these individual products at different pressures and temperatures, which are computed by multiplying the total rate coefficients with the product branching ratios. In the phenyl $+\mathrm{O}_{2}$ reaction, at the lowest pressure of $0.01 \mathrm{~atm}$ and a temperature of $1500 \mathrm{~K}$, a large fraction of phenoxy radicals equilibrate rather than dissociate and the computed rate coefficients for the formation of the $\mathrm{C}_{6} \mathrm{H}_{5} \mathrm{O}+\mathrm{O}$ and $\mathrm{C}_{5} \mathrm{H}_{5}+\mathrm{CO}+\mathrm{O}$ products are $1.74 \times 10^{-11}$ and $7.06 \times 10^{-12} \mathrm{~cm}^{3}$ molecule $\mathrm{s}^{-1}$, with their respective branching ratios being 0.59 and 0.24 , respectively. However, dissociation becomes more favorable than equilibration with a further temperature increase, and the rate coefficient to produce $\mathrm{C}_{5} \mathrm{H}_{5}+\mathrm{CO}+\mathrm{O}$ and its branching ratio rise to $3.90 \times 10^{-11} \mathrm{~cm}^{3}$ molecule $\mathrm{s}^{-1}$ and 0.94 , respectively. The rate coefficient and branching ratio for the reaction channel leading to $\mathrm{C}_{6} \mathrm{H}_{5} \mathrm{O}+\mathrm{O}$ drop to $1.33 \times 10^{-12} \mathrm{~cm}^{3}$ molecule $\mathrm{s}^{-1}$ and 0.03 , respectively. The increase in pressure at constant temperature increases the yield of equilibrated $\mathrm{C}_{6} \mathrm{H}_{5} \mathrm{O}$ and accordingly the rate coefficient to form this product. Since the combined branching ratio of the two products is pressure-independent, the pressure increase also reduces the yield and the rate coefficient for $\mathrm{C}_{5} \mathrm{H}_{5}+\mathrm{CO}+\mathrm{O}$. Nevertheless, even at the highest pressure of 10 atm and temperature of $2500 \mathrm{~K}$ most of phenoxy radicals dissociate and the branching ratio of $\mathrm{C}_{5} \mathrm{H}_{5}+\mathrm{CO}+\mathrm{O}$ is still 0.61 vs. 0.36 for equilibrated $\mathrm{C}_{6} \mathrm{H}_{5} \mathrm{O}+\mathrm{O}$.

The 1-naphthyl $+\mathrm{O}_{2}$ reaction shows similar trends but with two caveats. First, the combined branching ratios of $1-\mathrm{C}_{10} \mathrm{H}_{7} \mathrm{O}+\mathrm{O} /$ indenyl $+\mathrm{CO}+\mathrm{O}$ are lower than the respective values for $\mathrm{C}_{6} \mathrm{H}_{5} \mathrm{O}+\mathrm{O} / \mathrm{C}_{5} \mathrm{H}_{5}+\mathrm{CO}+\mathrm{O}$ and hence, the individual rate coefficients of both 1-naphthoxy and indenyl product channels are lower as compared to those for phenoxy and cyclopentadienyl. Second, the decomposition of chemicallyactivated 1-naphthoxy radicals to indenyl+CO from the 1-naphthyl+O $\mathrm{O}_{2}$ reaction is generally less favorable than the decomposition of chemically-activated phenoxy radicals from phenyl+O $\mathrm{O}_{2}$. As a result, at the high pressure of $10 \mathrm{~atm}$, which strongly favors the equilibration process, the computed branching 
ratio of indenyl $+\mathrm{CO}+\mathrm{O}, 0.34$, remains lower than the respective value of 0.43 for 1 -naphthoxy+O even at the highest temperature of $2500 \mathrm{~K}$.

The 2-naphthyl $+\mathrm{O}_{2}$ reaction exhibits similar trends: the relative yield for the indenyl $+\mathrm{CO}+\mathrm{O}$ decomposition products and the respective rate coefficient increase with temperature and decrease with pressure, whereas the opposite behavior is observed for the equilibrated 2-naphthoxy product. However, the decomposition process in this system appears to be significantly more favorable. At the lowest pressure of $0.01 \mathrm{~atm}$, least conducive for equilibration, the branching ratio of indenyl+CO+O ranges from 0.66 at $1500 \mathrm{~K}$ to 0.95 at $2500 \mathrm{~K}$, with that for equilibrated 2-naphthoxy+O being 0.15 and 0.00 , respectively.

The 2-naphthoxy+O product becomes more favorable than indenyl only at the higher pressures of 1 and 10 atm and only at our lowest temperature of $1500 \mathrm{~K}$, whereas at higher temperatures, especially at $2500 \mathrm{~K}$, indenyl remains the dominant product. Again, the differences in the branching ratios of the $\mathrm{C}_{5} \mathrm{H}_{5}+\mathrm{CO}+\mathrm{O}$ and indenyl $+\mathrm{CO}+\mathrm{O}$ decomposition products can be traced back to the PESs for the fragmentation of phenoxy and 1- and 2-naphthoxy radicals. The critical barriers on their dissociation pathways were computed to be $53.8,58.2$, and $48.3 \mathrm{kcal} / \mathrm{mol}$, respectively $[12,20]$, clearly indicating that the decomposition process is most favorable for 2-naphthoxy and least favorable for 1-naphthoxy, in line with the observed trends in the branching ratios. In turn, the difference in the barrier heights for the phenoxy and naphthoxy radicals can be attributed to the difference in the relative stability of the bi(tri)cyclic intermediates 4 (phenoxy), a4 (1-naphthoxy), and b4 (2-naphthoxy) [12,20], where a4 is destabilized as compared to 4 due to the rigidity introduced by the presence of the additional $\mathrm{C}_{6}$ ring next to the rearrangement site, but $\mathbf{b 4}$ in contrast is stabilized by extra electronic delocalization owing to the presence of the additional ring away from the rearrangement site.

\section{Conclusions}


Theoretical VRC-TST/RRKM-ME calculations show that total rate coefficients for the oxidation reactions of aromatic phenyl and naphthyl radicals with $\mathrm{O}_{2}$ at combustion-relevant temperatures of $1500-2500 \mathrm{~K}$ and pressures of $0.01-10$ atm are in the range of $3.0-5.5 \times 10^{-11} \mathrm{~cm}^{3}$ molecule $\mathrm{s}^{-1}$ and exhibit positive temperature dependence with activation energies of $2.3-3.3 \mathrm{kcal} / \mathrm{mol}$ and preexponential factors of $7-10 \times 10^{-11} \mathrm{~cm}^{3}$ molecule $^{-1} \mathrm{~s}^{-1}$. The phenyl $+\mathrm{O}_{2}$ and 1-naphthyl $+\mathrm{O}_{2}$ rate coefficients are similar to each other, whereas those for 2-naphthyl $+\mathrm{O}_{2}$ are $15-30 \%$ higher. The dominant channel for all three oxidation reactions is elimination of the oxygen atom from peroxy complexes formed at the initial $\mathrm{O}_{2}$ addition step and leading to phenoxy and naphthoxy radical products. The contribution of this channel increases with temperature. For phenyl+ $\mathrm{O}_{2}$, a small but significant yield of pyranyl+CO, 0.10, is observed at the lowest temperature of $1500 \mathrm{~K}$. For 1-naphthyl+O $\mathrm{O}_{2}$, the branching ratio of 1-benzopyranyl+CO at $1500 \mathrm{~K}$ is somewhat higher, 0.24 , and those for 1,2 naphthobenzoquinone $+\mathrm{H}$ and indenyl $+\mathrm{CO}_{2}$ also slightly exceed 0.10 . In contrast, the relative yields of 2-benzopyranyl, indenyl, and 1,2-naphthobenzoquinone are found to be minor for the 2-naphthyl+O $\mathrm{O}_{2}$ reaction over the entire $1500-2500 \mathrm{~K}$ temperature range. Also, the relative yields of products formed after $\mathrm{O}$ insertion into an aromatic ring are independent of pressure.

Chemically-activated phenoxy and naphthoxy radicals can further decompose to cyclopentadienyl+CO and indenyl+CO, respectively, or undergo thermal equilibration. The branching of decomposition/equilibration products strongly depends on temperature and pressure, in the way that an increase in temperature favors decomposition and an increase in pressure favors equilibration. The decomposition process is found to be most favorable for 2-naphthoxy radical and least favorable for 1naphthoxy, with phenoxy radical being intermediate.

Our study shows that although the general trends in the oxidation kinetics of phenyl and naphthyl radicals are similar (similar rate coefficients, dominance of the $\mathrm{O}_{2}$ addition/O elimination channel, small but still significant yields of pyranyl-like products at lower temperatures), they may differ in details. The differences are attributed not only to the size of the aromatic species but also to the position of the 
radical site in the aromatic moiety. Further studies of the PESs and kinetics of larger polycyclic aromatic radicals, such as acenaphthyl, phenathryl, and anthracyl would be informative to generalize the new insights into the oxidation mechanisms of larger PAH. Although one the primary motivations for this study was to provide reaction rate data for larger PAHs and soot, a direct comparison between small PAH rate coefficient values, such as those computed in the present work, and experimental soot oxidation rates is not fully appropriate. A truly meaningful comparison requires considering a fuller set of reactions, not just oxidation of an "open" aromatic radical with $\mathrm{O}_{2}$, but also creation of such radical sites and competing reactions for those sites. More importantly, not all radical sites will undergo such oxidation; for example, as was established in a recent study [33], a radical site on a zigzag edge does not undergo oxidation. This is clearly a subject for future studies. The present rates are sufficiently fast (as compared to the values presently used in soot models) to allow for slower overall oxidation rates due to competing reactions or surface site unavailability.

\section{Acknowledgements}

This work was funded by the Chemical Sciences, Geosciences and Biosciences Division, Office of Basic Energy Sciences, Office of Sciences of the U.S. Department of Energy (Grant No. DE-FG0204ER15570 to FIU and Contract No. DE-AC03-76F00098 to LBNL) and by the US Army Corps of Engineers, Humphreys Engineering Center Support Activity (Contract No. W912HQ-11-C-0035 to

UCB). This research used resources of the National Energy Research Scientific Computing Center, which is supported by the Office of Science of the U.S. Department of Energy under Contract No. DE-AC02-05CH11231. 
Table 1. Total bimolecular rate coefficients of product formation $\left(\right.$ in $\mathrm{cm}^{3}$ molecule $\mathrm{e}^{-1} \mathrm{~s}^{-1}$ ) calculated at different temperatures and $p=1 \mathrm{~atm}$.

\begin{tabular}{|l|c|c|c|}
\hline$T, \mathrm{~K}$ & phenyl $+\mathrm{O}_{2}$ & 1-naphthyl+O & 2-naphthyl+O \\
\hline 1500 & $2.96 \times 10^{-11}$ & $3.08 \times 10^{-11}$ & $3.53 \times 10^{-11}$ \\
\hline 2000 & $3.46 \times 10^{-11}$ & $3.81 \times 10^{-11}$ & $4.58 \times 10^{-11}$ \\
\hline 2500 & $4.16 \times 10^{-11}$ & $4.20 \times 10^{-11}$ & $5.49 \times 10^{-11}$ \\
\hline
\end{tabular}

\section{Figure Captions}

Figure 1. Comparison of the calculated total rate coefficients of the phenyl $+\mathrm{O}_{2}$ reaction with the experimental data at $T=418-815 \mathrm{~K}$ (from [14]).

Figure 2. Temperature dependence of product branching ratios of the phenyl $+\mathrm{O}_{2}(\mathrm{a}), 1$-naphthyl $+\mathrm{O}_{2}(\mathrm{~b})$, and 2-naphthyl $+\mathrm{O}_{2}$ (c) reactions. Combined branching ratios are shown for the $\mathrm{C}_{6} \mathrm{H}_{5} \mathrm{O}+\mathrm{O} / \mathrm{C}_{5} \mathrm{H}_{5}+\mathrm{CO}+\mathrm{O}$, 1- $\mathrm{C}_{10} \mathrm{H}_{7} \mathrm{O}+\mathrm{O} /$ indenyl $+\mathrm{CO}+\mathrm{O}$, and $1-\mathrm{C}_{10} \mathrm{H}_{7} \mathrm{O}+\mathrm{O} /$ indenyl+CO+O products.

Figure 3. Rate coefficients for the formation of the $\mathrm{C}_{6} \mathrm{H}_{5} \mathrm{O}+\mathrm{O}$ and $\mathrm{C}_{5} \mathrm{H}_{5}+\mathrm{CO}+\mathrm{O}$ products in the phenyl $+\mathrm{O}_{2}$ reaction (a), $1-\mathrm{C}_{10} \mathrm{H}_{7} \mathrm{O}+\mathrm{O}$ and indenyl $+\mathrm{CO}+\mathrm{O}$ in the 1-napthyl $+\mathrm{O}_{2}$ reaction (b), and 2$\mathrm{C}_{10} \mathrm{H}_{7} \mathrm{O}+\mathrm{O}$ and indenyl $+\mathrm{CO}+\mathrm{O}$ in the 2-napthyl $+\mathrm{O}_{2}$ reaction (c) calculated at different temperatures and pressures. 


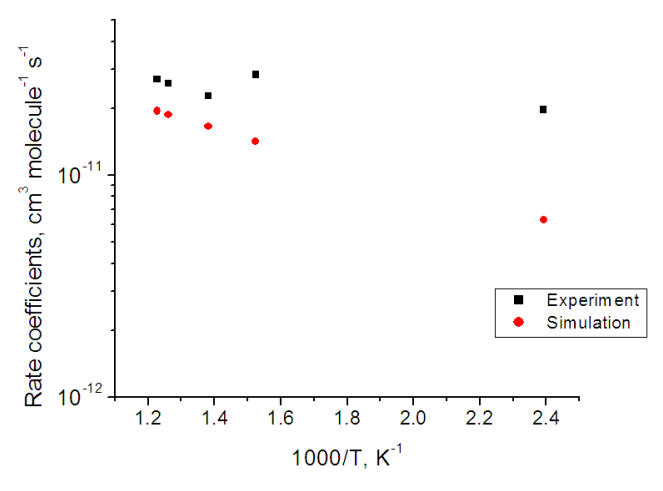

Figure 1 
(a) phenyl $+\mathrm{O}_{2}$
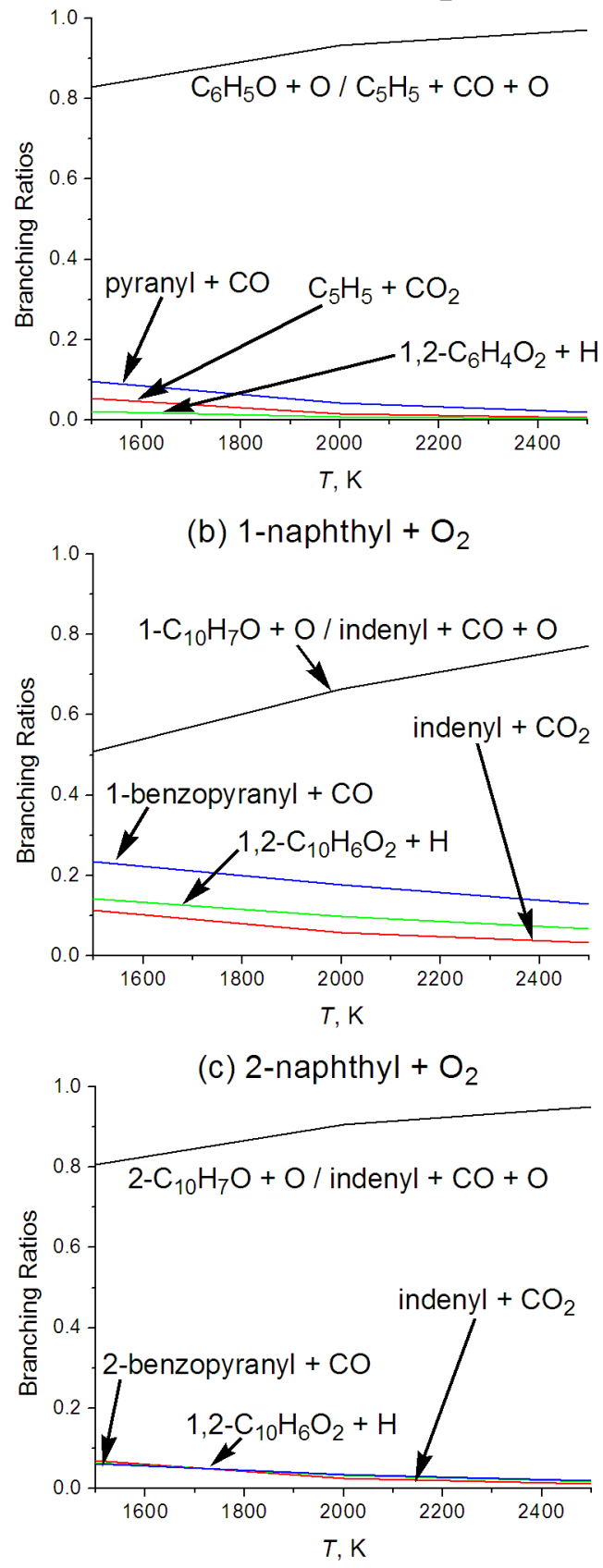

Figure 2 


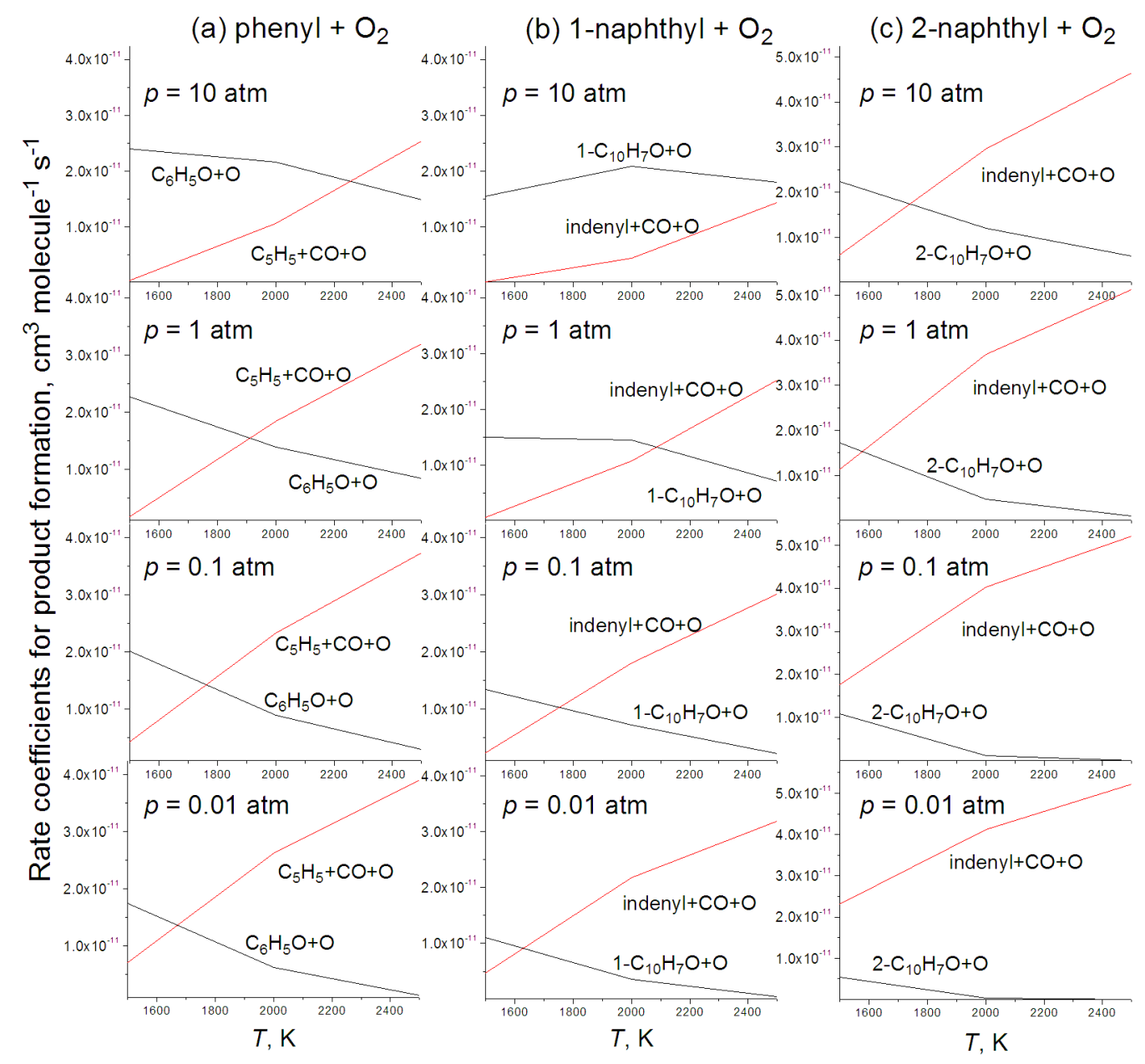

Figure 3 


\section{References}

[1] H. Richter, J.B. Howard, Prog. Energy Combust. Sci. 26 (2000) 565.

[2] C.-Y. Lin, M.C. Lin, J. Phys. Chem. 90 (1986) 425.

[3] J. Herzler, P. Frank, Third International Conference on Chemical Kinetics, NET, Gaithersburg, MD, July 12-16, 1993.

[4] P. Frank, J. Herzler, Th. Just, C. Wahl, Proc. Combust. Inst. 25 (1994) 833.

[5] T. Yu, M.C. Lin, J. Am. Chem. Soc. 116 (1994) 9571.

[6] B.K. Carpenter, J. Am. Chem. Soc. 115 (1993) 9806.

[7] A.M. Mebel, M.C. Lin, J. Am. Chem. Soc. 116 (1994) 9577.

[8] M.C. Lin, A.M. Mebel, J. Phys. Org. Chem. 8 (1995) 407.

[9] M.J. Fadden, C. Barckholtz, C.M. Haddad, J. Phys. Chem. A 104 (2000) 3004.

[10] M.J. Fadden, C.M. Hadad, J. Phys. Chem. A 104 (2000) 8121.

[11] J.K. Merle, C.M. Hadad, J. Phys. Chem. A 108 (2004) 8419.

[12] I.V. Tokmakov, G.S. Kim, V.V. Kislov, A.M. Mebel, M.C. Lin, J. Phys. Chem. A 109 (2005) 6114.

[13] G. Silva, J.W. Bozzelli, J. Phys. Chem. A 112 (2008) 3566.

[14] J. Schaugg, R.S. Tranter, H.-H. Grotheer, Transport Phenomena in Combustion, Proceedings of the $8^{\text {th }}$ International Symposium on Transport Phenomena in Combustion, San Francisco, Taylor \&

Francis, Washington, D. C., 1995, p. 130, CODEN: 63UGAB.

[15] X. Gu, F. Zhang, R.I. Kaiser, Chem. Phys. Lett. 448 (2007) 7-10.

[16] D.S.N. Parker, F. Zhang, R.I.Kaiser, J. Phys. Chem. A 115 (2011) 11515-11518.

[17] D.R. Albert, H.F. Davis, J. Phys. Chem. Lett. 1 (2010) 1107-1111.

[18] N.M. Marinov, W.J. Pitz, C.K. Westbrook, A.M. Vincitore, M.J. Castaldi, S.M. Senkan, Combust. Flame 114 (1998) 192.

[19] J. Park, Z.F. Xu, M.C. Lin, J. Phys. Chem. A 113 (2009) 5348.

[20] C.-W. Zhou, V.V. Kislov, A.M. Mebel, J. Phys. Chem. A 116 (2012) 1571-1585. 
[21] S.J. Klippenstein, Chem. Phys. Lett. 170 (1990) 71-77.

[22] S.J. Klippenstein, A.F. Wagner, R.C. Dunbar, D.M. Wardlaw, S.H. Robertson, VARIFLEX, version $1.0,1999$.

[23] M.J. Frisch, G.W. Trucks, H.B. Schlegel, G.E. Scuseria, M.A. Robb, J.R. Cheeseman, V.G. Zakrzewski, J.A. Montgomery, R.E. Stratmann, J.C. Burant, S. Dapprich, J.M. Millam, R.E. Daniels, K.N. Kudin, M.C. Strain, O. Farkas, J. Tomasi, V. Barone, M. Cossi, R. Cammi, B. Mennucci, C. Pomelli, C. Adamo, S. Clifford, J. Ochterski, G.A. Petersson, P.Y. Ayala, Q. Cui, K. Morokuma, P. Salvador, J.J. Dannenberg, D.K. Malick, A.D. Rabuck, K. Raghavachari, J.B. Foresman, J. Cioslowski, J.V. Ortiz, A.G. Baboul, B.B. Stefanov, G. Liu, A. Liashenko, P. Piskorz, I. Komaromi, R. Gomperts, R.L. Martin, D.J. Fox, T. Keith, M.A. Al-Laham, C.Y. Peng, A. Nanayakkara, M. Challacombe, P.M.W. Gill, B. Johnson, W. Chen, M.W. Wong, J.L. Andres, C. Gonzalez, M. Head-Gordon, E.S. Replogle, J. A. Pople, Gaussian 98, revision A.11, Gaussian, Inc., Pittsburgh, PA, 2001.

[24] R.D. Amos, A. Bernhardsson, A. Berning, P. Celani, D.L. Cooper, M.J.O. Deegan, A.J. Dobbyn, F. Eckert, C. Hampel, G. Hetzer, P.J. Knowles, T. Korona, R. Lindh, A.W. Lloyd, S.J. McNicholas, F.R. Manby, W. Meyer, M. E. Mura, A. Nicklaß, P. Palmieri, R. Pitzer, G. Rauhut, M. Schütz, U. Schumann, H. Stoll, A.J. Stone, R. Tarroni, T. Thorsteinsson, H.-J. Werner, MOLPRO version 2002.6, University of Birmingham,Birmingham, UK, 2003.

[25] DALTON, a molecular electronic structure program, Release 2.0 (2005), see http://www.kjemi.uio.no/software/dalton/dalton.html.

[26] J.R. Barker, Int. J. Chem. Kinet. 33 (2001) 232-245.

[27] J.R. Barker, Int. J. Chem. Kinet. 41 (2009) 748-763.

[28] J.R. Barker, N.F. Ortiz, J.M. Preses, L.L. Lohr, A. Maranzana, P.J. Stimac, T.L. Nguyen, T.J.D. Kumar, MultiWell Software, 2012.2, University of Michigan, Ann Arbor, MI, 2012; http://aoss.engin.umich.edu/multiwell/.

[29] R.G. Gilbert, S.C. Smith, Theory of Unimolecular and Recombination Reactions. Blackwell- 
Scientific, Oxford, U.K., 1990.

[30] D.E. Edwards, X. You, D.Y. Zubarev, W.A. Lester Jr, M. Frenklach, Proc. Combust. Inst. 34 (2013) 1759-1766.

[31] H. Wang, M. Frenklach, Combust. Flame 96 (1994) 163-170.

[32] R. Whitesides, D. Domin, R. Salomón-Ferrer, W.A. Lester, Jr., M. Frenklach, J. Phys. Chem. A 112 (2008) 2125-2130.

[33] X. You, D. Yu. Zubarev, W. A. Lester, Jr., M. Frenklach, J. Phys. Chem. A 115 (2011), 1418414190. 